University of Wollongong

Research Online

Faculty of Business - Papers (Archive)

Faculty of Business and Law

$1-1-2017$

Robot induced technological unemployment: towards a youth-focused coping strategy

Eduardo Pol

University of Wollongong, epol@uow.edu.au

James Reveley

University of Wollongong, jreveley@uow.edu.au

Follow this and additional works at: https://ro.uow.edu.au/buspapers

Part of the Business Commons

Research Online is the open access institutional repository for the University of Wollongong. For further information contact the UOW Library: research-pubs@uow.edu.au 


\title{
Robot induced technological unemployment: towards a youth-focused coping strategy
}

\author{
Abstract \\ As an agent of economic and social change, robotization has elicited considerable concern about \\ technological unemployment. Focusing on youth, this paper makes four contributions to the debate over \\ this labour-displacing technological change's effects. First, to clarify the magnitude of the job threat to \\ young people, the paper accentuates the conceptual distinction between technological unemployment \\ and frictional unemployment. Second, the possibility of persistent technological unemployment, which \\ the young are currently facing, is linked to strong uncertainty stemming from the rapidity of invention in \\ robotics and artificial intelligence. Third, the paper advances a plausibility-based argument about the \\ inevitability of technological unemployment. Fourth, coping behaviour is shown to be logically compatible \\ with rationality and well-suited to dealing with fear of joblessness. Fifth, to the extent that robotization \\ threatens future jobs, we maintain that coping strategies are needed to help members of the younger \\ generation. A resilience-based strategy is suggested but we believe that there may be other coping \\ strategies complementary to our proposal.
}

\section{Keywords}

robot, unemployment:, strategy, towards, technological, coping, youth-focused, induced

\section{Disciplines}

Business

\section{Publication Details}

Pol, E. \& Reveley, J. (2017). Robot induced technological unemployment: towards a youth-focused coping strategy. Psychosociological Issues in Human Resource Management, 5 (2), 169-186. 


\title{
ROBOT INDUCED TECHNOLOGICAL UNEM PLOYMENT: TOWARDS A YOUTH-FOCUSED COPING STRATEGY
}

\author{
EDUARDO POL \\ epol@uow.edu.au \\ Centre for Small Business and Regional Research, \\ Faculty of Business, \\ School of Accounting, Economics and Finance, \\ The University of Wollongong \\ JAMES REVELEY \\ jreveley@uow.edu.au \\ School of Management, Operations and Marketing, \\ Faculty of Business, \\ The University of Wollongong \\ (corresponding author)
}

\begin{abstract}
As an agent of economic and social change, robotization has elicited considerable concern about technological unemployment. Focusing on youth, this paper makes four contributions to the debate over this labour-displacing technological change's effects. First, to clarify the magnitude of the job threat to young people, the paper accentuates the conceptual distinction between technological unemployment and frictional unemployment. Second, the possibility of persistent technological unemployment, which the young are currently facing, is linked to strong uncertainty stemming from the rapidity of invention in robotics and artificial intelligence. Third, the paper advances a plausibility-based argument about the inevitability of technological unemployment. Fourth, coping behaviour is shown to be logically compatible with rationality and well-suited to dealing with fear of joblessness. Fifth, to the extent that robotization threatens future jobs, we maintain that coping strategies are needed to help members of the younger generation. A resilience-based strategy is suggested but we believe that there may be other coping strategies complementary to our proposal.
\end{abstract}

\section{JEL codes: E24; J21; J54; J64}

Keywords: robot; uncertainty; unemployment; coping; resilience; mindfulness

How to cite: Pol, Eduardo, and James Reveley (2017). "Robot Induced Technological Unemployment: Towards a Youth-Focused Coping Strategy," Psychosociological Issues in Human Resource Management 5(2): 169-186.

Received 29 September 2017 • Received in revised form 1 November 2017 Accepted 2 November 2017 • Available online 20 November 2017 


\section{Introduction}

An important uncertainty associated with the introduction of innovations is the unpredictability of their impact on future generations. Labour-saving innovations have a long history as a source of worker anxiety. Concerns about workers who are thrown out of their jobs as a result of labour-displacing technologies go back at least to Ned Ludd's destruction of two stocking frames in 1779 near Leicester, England. Recorded economic history shows, however, that the introduction of labour-saving innovations did not result in persistent technology induced unemployment and fear of joblessness remained bounded (Headrick, 2009).

Of course, what was true in the past may not be true in the future. Due to the advance of robotics and artificial intelligence, the shadow of unemployment caused by technical progress once again looms large on the horizon (Radinsky, 2015). At the forefront of current labour-saving technologies, robots have the potential to transform not just individual firms but whole industries and even entire economies. In our usage, "robot" functions as a cluster concept that "refers broadly to any sort of machinery, from computers to artificial intelligence programs, that provides a good substitute for work currently performed by humans" (Freeman, 2015: 2). Machines make cars, write articles, diagnose diseases, and are encroaching on all sorts of professions, including but not limited to, teaching, accounting, and law. It is not unreasonable to ask: Will there be any jobs left for humans? This question is of vital importance to the life-chances and well-being of young people.

The French social philosopher Bernard Stiegler, a scholar with a keen interest in how technology affects the younger generation, warns of an "immense transformation" (Stiegler, 2015: 126) as automation replaces jobs. Judging by recent work on this topic (Brynjolfsson \& McAfee, 2011; Ford, 2015), simply telling young people to get more education, training and skills to protect themselves against the possibility of job loss is looking more like a questionable labour economistic mantra than unambiguously sound career advice. That such advice is still being given is perhaps no surprise; classic career theory has tended to ignore how career formation is disrupted by substantial economic change (Kanter, 1995). The whole notion of enhanced employability, to help young people deal with low job prospects and employment insecurity, also now seems questionable (Crisp \& Powell, 2016).

This present conceptual paper contributes to the current debate over robots, technological unemployment, and youth job futures (see Peters, 2016). The pace with which robotization is advancing - we argue - means that young people are confronted by a job market wherein the nature of uncertainty has undergone a qualitative shift. The standard economic approach to labour market uncertainty - wherein all possible outcomes are known and proba- 
bilities can be assigned to them - no longer applies. This is because of strong uncertainty, a concept that we explicate in 2.2. This uncertainty, in turn, has implications for what is, and what is not a rational response on the part both of young jobseekers and policymakers seeking to bolster the life-chances of this population group. In a nutshell, under these uncertainty conditions coping behaviour, far from being inherently irrational, is supremely rational. Coping strategies, therefore, cannot be ruled out by economists and other social scientists who prize rational behaviour and policy responses built on that foundation. Ultimately, our paper provides a justificatory framework for discussing the plausibility of designing a strategy to help young people cope with the challenge of the current wave of labour-displacing technological change.

Our article is structured as follows. Section 2 introduces working definitions of the key concepts we employ. Technological unemployment (2.1) resolves conceptual imprecision in the literature. Strong uncertainty (2.2) is a necessary building block to discuss whether the economy is moving towards robot induced technological unemployment. Shackle's potential surprise theory (2.3) is used to make a plausibility-based argument that this unemployment is not unlikely. Section 3 focuses on coping with uncertainty. Rationality of coping behaviour (3.1) demonstrates logically that coping behaviour is a rational response to life under conditions of strong uncertainty. Crafting a coping strategy (3.2) offers some suggestions for a resiliencebased strategy to help members of the younger generation deal with the job threat posed by robotization. Section 4 consists of a summary and some concluding remarks.

\section{Key Theoretical Concepts}

This section seeks to introduce greater conceptual rigour into the debate over the socioeconomic impact of robotization. Imprecise use of theoretical concepts is an impediment to rational argumentation, because clearly defined concepts are the basic building blocks of logical reasoning. The latter is a prerequisite to understanding and therefore effectively responding to social problems - in this case, the effects of robots on the job prospects of the young. We focus on two key concepts: (a) technological unemployment, and (b) uncertainty. These, we argue, are related in the sense that a particular type of uncertainty results from technological unemployment, as we define it.

\subsection{Technological unemployment}

Far from being self-evident, technological unemployment is conceptually a subtle notion that dates back to the days of the classical economist David 
Ricardo (1772-1823). The shibboleth at the time was "the machinery question," as posed by Ricardo, namely whether machinery reduced the demand for labour. In the third (and last edition) of The Principles of Political Economy and Taxation, published in 1821, Ricardo added a new chapter entitled "On Machinery," in which he analysed the effect on the economy of the introduction of machinery. With regard to wage-earners, Ricardo's conviction was striking:

I am convinced that the opinion entertained by the labouring class, that employment of machinery is frequently detrimental to their interests, is not founded on prejudice and error, but is conformable to the correct principles of political economy. (Ricardo, 1911: 264)

After two centuries, the machinery question is back on the agenda. In the wider literature on the socioeconomic impact of robotics and artificial intelligence, however, there is no generally agreed definition of technological unemployment. Danaher's (2016) attempt to identify two different versions - short-term and long-term - shows that technological unemployment is a contested concept. The intuition behind the concept is that new technologies displace workers faster than the economy can find new jobs for them. This idea is, in fact, evident in the work of John Maynard Keynes, the first economist who explicitly defined the term:

We are being affected with a new disease of which some readers may not have yet heard the name, but of which they will hear a great deal in the years to come - namely, technological unemployment. This means unemployment due to our discovery of means of economising the use of labour outrunning the pace at which we can find new uses for labour. (Keynes, 1930: 325, original emphasis)

Thus, according to Keynes, the defining characteristic of technological unemployment is that the pace at which new uses of labour are found is less than the pace of the number of jobs taken by machines. This definition is so commonplace that it is used intuitively in the literature on robotization (cf. Marchant, Stevens, \& Hennessy, 2014; Saner \& Wallach, 2015). Unfortunately, however, intuitive understandings can lead to technological unemployment being conflated with frictional unemployment. A recent paper on machine intelligence by Loi (2015) is a case in point.

Certainly, Keynes's definition captures one of the distinguishing features of the concept in question, namely: the rate at which the system economizes the use of labour is greater than the rate of creation of new jobs. This intuitive definition is good as a first approximation but not as a second because it remains silent about a critical point: do the workers displaced by new technologies ever get a job? New technologies such as, for example, the growing 
ubiquity of self-checkout at supermarkets and drug stores may temporarily displace workers but a growing economy may quickly create jobs for these workers. The intuitive definition renders technological unemployment observationally equivalent to frictional unemployment. ${ }^{1}$

In order to elaborate our alternative definition of technological unemployment, a piece of notation is necessary here. Let $\mathrm{R}(\mathrm{t})$ and $\mathrm{H}(\mathrm{t})$ be the number of jobs taken by robots and the number of jobs taken by humans in year $t$, respectively. We assume that each job can be performed either by a person or by a robot, each person performs only one job, and the decision to allocate a worker or a robot to a particular job is dictated by cost-minimization. The number of unemployed people $\mathrm{U}(\mathrm{t})$ is the difference between the number of workers willing to take a job at the prevailing wage rate $\mathrm{N}(\mathrm{t})$ and the total number of employed people, that is, $\mathrm{U}(\mathrm{t})=\mathrm{N}(\mathrm{t})-\mathrm{H}(\mathrm{t}))$. Technological unemployment only occurs when the increase in the number of jobs taken by robots in $t+1$ is greater than the number of jobs taken by humans in $t+1$, that is, $\mathrm{R}(\mathrm{t}+1)-\mathrm{R}(\mathrm{t})>\mathrm{H}(\mathrm{t}+1)-\mathrm{H}(\mathrm{t})$.

The economy that we have in mind is a competitive, profit-oriented, market-guided economy displaying economic growth and population growth. Robots or smart machines are means of economizing the use of labour. This signals that the prime mover of human replacement is the profit motive. It is clear that labour-saving technological change means that machines provoke human replacement at the workplace. What may not be as obvious is that according to our alternative definition - this sort of technological change does not necessarily imply technological unemployment; the net effect may simply be frictional unemployment. Furthermore, frictional unemployment (namely, the unemployment that arises from the process by which workers find appropriate jobs given their skills and tastes) is captured by $\mathrm{U}(\mathrm{t})$.

\subsection{Strong uncertainty}

A univocal concept has a single meaning and one empirical referent. Uncertainty is not like that; there are different forms of uncertainty. The uncertainty resulting from the operation of the economy today is qualitatively different from the uncertainty individuals and businesses experienced under capitalism in the twentieth century. A distinction between two kinds of uncertainty introduced by the American economist Frank H. Knight (18851973) almost a century ago is particularly relevant today. Everyone knows that uncertainty means that we do not know what is going to happen. What Knight emphasized was that when dealing with uncertainty one has to be aware of a key dichotomy.

Paraphrasing Knight (1965), one can say that sometimes we face weak uncertainty in that we are able to specify all the possible outcomes together with their corresponding probabilities (e.g. buying a lottery ticket). At other 
times, we face strong uncertainty where it is not possible to define, or even imagine, all future outcomes, so probabilities cannot therefore be attached to them. A simple thought experiment can clarify this conceptual distinction. ${ }^{2}$ Suppose time travelling to the past is possible; locate oneself at the beginning of the twentieth century, and then try to imagine the launching of the Internet in 1995. The point is that, in the case of fundamental technological shifts, past experiences and events are no guide to future developments and outcomes.

As we shall see, this bifurcation of the concept of uncertainty has profound implications not only for thinking about how young people might deal with the effects of labour-displacing technological change on their life chances, but also for what it means to be rational. To the extent that reasoning about future states of affairs is based on probabilities, it is inductive in nature. Yet, under conditions of strong uncertainty inductive (probabilistic) reasoning fails, to the extent that "the future will not be relevantly like the past" (Feser, 2017: 152). If the future is not going to be relevantly like the past, being rational in the sense of developing arguments based on probabilities is, therefore, impossible. Below we switch to plausibility as the criterion for trying to determine robotization's effects on employment.

\subsection{From probability to plausibility: Shackle's potential surprise theory}

In view of strong uncertainty, should scholars give up any hope of identifying the likely employment outcomes of robotization? We think not. One possibility is to use G.L.S. Shackle's Potential Surprise Theory (PST) to advance an argument to support the hypothesis that robotization is not actually going to be employment-creating, and, in consequence, that there is a real likelihood of technological unemployment developing.

PST theory is suitable for the task at hand for the simple reason that it is based on plausibility rather than probability (Shackle, 1938). Shackle's most enduring contribution was to show why probability is an inappropriate means for considering any sort of possible development - including employment futures - under strong uncertainty. In fact, Shackle identified the Achilles heel of probability theory: the problem of "additivity" (Shackle, 1955: 68-74). Broadly speaking, this problem can be described as follows. The Kolmogorov axioms which underpin probability theory postulate that all possible outcomes are known in advance (the problem is said to be "closed"), that is, the probability that one out of all outcomes comprising the outcome space will occur is equal to one. Under circumstances of strong uncertainty, the future is open and therefore the problem is not a closed one.

Though there is an extensive academic literature on PST it is not necessary, for this paper's purposes, to rehearse the debates. Instead, we draw on work by Earl and Littleboy (2014) and Zappia (2014) that channels Shackle's 
argument. The broad lines are as follows. When analysts evaluate the plausibility of occurrence of a future outcome (FO) under current conditions, they tend to envisage two polar cases to frame the analysis: the occurrence of FO seems completely impossible $\left(\mathrm{PC}_{1}\right)$ and the occurrence of the FO seems completely possible. It is clear that the analysts can establish a correspondence between "degree of belief" (how possible or impossible the FO seems) or "degree of plausibility" and "degree of surprise." Given a posited FO, how surprised would the analysts be if this outcome occurred? While in polar case $\mathrm{PC}_{1}$ the analysts would be very surprised indeed with the occurrence of the $\mathrm{FO}$, exactly the opposite would happen with polar case $\mathrm{PC}_{2}$; that is, the analysts would not be surprised at all with the occurrence of FO (see Table 1).

Table 1 Outline of PST

\begin{tabular}{|l|l|l|l|}
\hline $\begin{array}{l}\text { Polar } \\
\text { case }\end{array}$ & FO: occurrence seems & Degree of plausibility & $\begin{array}{l}\text { Degree of } \\
\text { surprise }\end{array}$ \\
\hline $\mathrm{PC}_{1}$ & Completely impossible & Null & Absolute \\
\hline $\mathrm{PC}_{2}$ & Completely possible & Absolute & Null \\
\hline
\end{tabular}

It is our view that the FO described as "creative destruction associated with robotization will create more human jobs in total than it destroys" (or, to put it somewhat roughly, "robotization will be economy-wide labour-augmenting") lacks plausibility.

Why will labour-saving technological change this time not be, as it has been before, employment-creating? There is a good reason to believe that the current round of labour-saving technological change is different. Robotization not only replaces muscular effort but also mental functions involved in many productive activities, and thereby, renders human labour increasingly superfluous. The empirical evidence suggests that almost anything a human can do, robots can do better (Nazareth, 2015; Hanson, 2016). This point has economic corollaries. Firstly, the ability of the service sector to absorb displaced human labour may well be diminished because the creation of increasingly efficient robots seems to have no limits (Ford, 2015). Consider the case of hotels where the concierge is a robot and that of robots assisting residents in nursing homes. Secondly, we are aware of no published evidence to support the view that technological responses to changes in factor prices resulting from the incessant introduction of robot-based products will lead to the creation of labour-intensive tasks. Each of these points lends credence to the (labour-augmenting) FO's implausibility.

Now, detractors may argue that the FO is in fact highly plausible based on historical experience. To argue this way involves drawing inferences about events in the future from events in the past. A typical argument would be that, in the past - when people had exactly the same fears about technical 
progress as they have today - in every instance the increased automation resulted in a rise in employment due to its labour productivity-enhancing effects, and the consequences of this for aggregate demand. Following this train of thought, automation is a double-edged sword. Unemployment due to new technology worsens income inequality and wealth disparity, but these are offset by gains in productivity and economic growth.

Yet, for two reasons we disagree that the preceding argument holds in the case of robotization. The first is that incessant innovation in robotics and artificial intelligence may generate an immiserating vicious circle. New and improved robots may bring about a wealth transfer from relatively unskilled young people to ourselves that leaves not just young people, but rather all our descendants worse off. Indeed, assume that new versions of robots substitute directly for young unskilled labour, but complement older skilled labour. The depression in wages of the young then limits their ability to invest in their own skill acquisition (for example, pursuing tertiary studies becomes increasingly difficult) and in physical capital (think of housing unaffordability). This, in turn, means that the next generation of young, initially unskilled workers encounter an economy with less human capital, which further drives down their wages. As a result, robotization may entail each new generation being worse off that their predecessor.

Our second point is that any claim about automation tending to increase employment must, of necessity, be based on historical extrapolations - which are difficult to ground under conditions of strong uncertainty (Staley, 2002). To be sure, our application of PST requires openness to understanding the connection between past, present, and future in terms of discontinuity rather than continuity or linear progress (Sewell, 2005). Yet, in the domain of technology, this is not without precedent. Schwab (2017), for one, argues that the fourth industrial revolution - of which artificial intelligence is the sine qua non - is reshaping the socioeconomic landscape in a manner qualitatively different from the preceding three such revolutions. Similarly, Barrat (2013) maintains we are entering a technological new era. The implication is clear: under frame-breaking technological change, the future is not merely a rerun of the past. Taken together, the various complementary points adduced above that offset robotization's potential for productivity-enhancement - namely: the service sector's limited absorptiveness, the lack of evidence about the effects of changing factor prices, the real possibility of an immiserating vicious circle, and the support Schwab and Barrat lend to the technological discontinuity thesis - allow us to draw what Spitzer (2015: 280) in another connection terms an "informal inference": the FO is implausible. Given this inference, one should not be surprised if technological unemployment eventuates. The results of the application of PST to robotization are summarized in Table 2. 
Table 2 Application of PST: robotization and technological unemployment

\begin{tabular}{|l|l|l|l|}
\hline $\begin{array}{l}\text { Robotization } \\
\text { (developing } \\
\text { apace) }\end{array}$ & $\begin{array}{l}\text { Plausibility of } \\
\text { occurrence }\end{array}$ & $\begin{array}{l}\text { Level of surprise } \\
\text { (assuming } \\
\text { occurrence) }\end{array}$ & $\begin{array}{l}\text { Technological } \\
\text { employment }\end{array}$ \\
\hline $\begin{array}{l}\text { Will be labour- } \\
\text { augmenting }\end{array}$ & $\begin{array}{l}\text { Highly } \\
\text { implausible }\end{array}$ & $\begin{array}{l}\text { Very surprised } \\
\text { indeed }\end{array}$ & Irrelevant \\
\hline $\begin{array}{l}\text { Will not be } \\
\text { labour- } \\
\text { augmenting }\end{array}$ & Highly plausible & Not all surprised & Inevitable \\
\hline
\end{tabular}

\section{Uncertainty and Coping}

With robotization developing apace, if it is correct to claim that increasing technological unemployment is a highly plausible occurrence, then one basic question immediately suggests itself. How can social scientists help young people to deal with the distress, despair and social dislocation that the joblessness threat is likely to cause? Job search under conditions of uncertainty is known to provoke negative emotions (Standing, 2011; Wilson \& Ebert, 2013), but the basis of the knowledge on which career advice can be given to the young is less than solid. For one thing, the extent of technological unemployment - the phenomenon's quantitative dimension - cannot be known in advance. For another thing, optimization of any sort is out of the question precisely because of strong uncertainty (which, to recapitulate, means that the best that can be provided is a plausibility argument concerning employment futures). A recent contribution by King (2016) provides a potential solution to the puzzle. The point forcibly made by King is that under conditions of strong uncertainty, a decision-maker has essentially two options: do nothing or engage in "coping behaviour."

\subsection{Rationality of coping behaviour}

To understand the crucial role of coping behaviour for decision making in general, it is helpful to pause for a moment to identify the distinguishing features of the concept itself. The loosest possible definition of coping behaviour is based on human nature. Humans seek to deal effectively with a changing reality by adapting and reacting, that is, by coping with the situation. The notion of coping behaviour is subtle. Optimizing behaviour and coping behaviour, in our view, are not mutually exclusive. Rather, optimizing behaviour is a particular case of coping behaviour. For example, in a freemarket economy the behaviour of businesses is consistent with the maximization of expected profits in the short-run. When the circumstances change, profit-maximizing firms respond by adjusting the optimal levels of production. When people confront strong uncertainty they respond and adapt as well, but 
the maximization of expected returns is not possible simply because the specification of all future outcomes is out of the question. Trying to optimize under strong uncertainty is like performing plastic surgery on an invisible patient; it is irrational. A syllogism can be used to summarize our argument:

(1) The pursuit of the impossible is irrational. (premise)

(2) Optimizing under strong uncertainty is impossible. (premise)

Therefore:

(3) Optimizing under strong uncertainty is irrational.

Figuratively, strong uncertainty creates an ignorance zone. The decision maker has to narrow down the ignorance zone and develop rules for sound decisions. Following King (2016), coping behaviour under conditions of strong uncertainty is based on a narrative and a set of heuristics. A narrative articulates pieces of information that appear to be relevant in order to narrow down the ignorance zone. The purpose of a narrative is twofold. It allows us to think about the future in qualitative terms and provides a platform for choosing the relevant heuristic. The heuristic, in turn, comprises rules of thumb to deal with different problems within the narrative. An obvious and not unimportant example is business innovation. Some innovative companies create a corporate motto such as "innovation everywhere and for everyone" to explain to staff members why the firm must be better at innovation. This narrative is accompanied by rules of thumb such as the new product must hit the market first, be underpinned by a superb technology, be three times better than the existing ones in relation to price, speed, and convenience, and so on.

The foregoing distinctions can be summarized in tabular form (see Table 3). One further issue implicit in Table 3 must be made explicit. Is coping behaviour always rational? At first glance, it would appear that coping behaviour under strong uncertainty is irrational because optimizing is out of the question. Simply put, there is nothing to be maximized or minimized.

Table 3 Two kinds of uncertainty

\begin{tabular}{|l|l|l|}
\hline Kind of Uncertainty & Coping Behaviour & Rules Provided By \\
\hline $\begin{array}{l}\text { Weak } \\
\text { (measurable uncertainty) }\end{array}$ & Optimizing & Mathematical formalisms \\
\hline $\begin{array}{l}\text { Strong } \\
\text { (unknowable future) }\end{array}$ & Non-optimizing & Heuristics \\
\hline
\end{tabular}

It should be clear that coping behaviour is a rational way to make decisions under conditions of weak uncertainty. In fact, rationality in the context of weak uncertainty means that the decision maker optimizes a well-defined objective function such as an expected returns function or a stochastic utility 
function. This explains why economists tend to conflate rationality with optimization.

A brief technical digression is worthwhile here. Optimization is a proper subset of mathematics, and mathematics is a proper subset of formal logic. Logical inference includes both formal logic and mathematics. Mathematical reasoning is essentially logical in character but mathematics necessitates the introduction of a concept foreign to formal logic: the concept of "infinity" (the infinitely large and the infinitely continuous). In brief, mathematics is formal logic extended in a particular direction to include the infinite as well as the finite.

Logical reasoning cannot and should not be identified with logical inference. Logical inference is a process of reasoning in which, granted the truth of the premises (assumptions), and if there are no errors in reasoning, the conclusions must be true. For example, assume that a firm maximizes profits. If the profit function is differentiable and gives rise to an inverted $\mathrm{U}$ profit curve, profit-maximization implies with logical compulsion that marginal revenue must be equal to marginal cost. In reliable inference the reasoning conducive to the conclusions does not enjoy logical compulsion, but there are reasons to believe that the conclusions are correct. For example, assuming economic freedom, private property, and many other conditions concerning institutions, labour market efficiency, and so forth, economists have reasons to believe that economic prosperity will follow.

Here is the critical point: coping behaviour is also a rational way of making decisions when the future is unknowable, when optimization is impossible and the most that can be used as a guide is plausibility-based envisioning. Under strong uncertainty, coping behaviour is rational in the sense that it is agreeable to reason and sound judgement. Logical inference is not ruled out, but reliable inference appears to be an essential ingredient of any coping strategy under strong uncertainty.

\subsection{Crafting a coping strategy}

Returning to the basic question, we believe that the answer requires the design of a coping strategy. The lineaments of a supporting narrative are not hard to sketch. Pervasive diffusion of information about the inexorable advance of robotization is needed to generate individual alertness and socio-political responsiveness. Arguably, a nascent narrative of that type is presently emerging. ${ }^{3}$ As contributors to this journal have recently observed, the creation and promulgation of narratives is central to envisaging better futures (Milojevic \& Iniyatulla, 2015; Iniyatulla, Izgarjan, Kuusi, \& Minkkinen, 2016). The central focus of the narrative in question would emphasize that robotization, despite being ineluctable, is a challenge to prevail over and not an immitigable threat. Then, to combat individual and social despair, a 
positive mindset can be encouraged and reinforced with a set of heuristics. Fostering social hope is the goal.

When it comes to heuristics, it would be reasonable to start with a common-sense rule of thumb: invest in social skills formation. Humans have a competitive advantage over robots in social interactional skills. One of the policy implications of the empirical work carried out by Frey and Osborne (2013) is that skills formation should be directed to social skills that robots, by their very nature, would find it difficult to acquire. Yet, as we have previously argued (2.3), the service industries where these skills are vital may simply not be able to absorb enough people who need jobs. As a result, we believe that resilience-enhancing emotion management skills must not only be added to the list of humans' competitive advantages; they must be accorded primacy. Increased resilience, we aver, can avert defeatism and hopelessness, and thus equip young people to confront the robotization challenge head-on.

Resilience has separable (but not unrelated) individual psychological and social systemic dimensions (Masten, 2014). At the individual level resilience denotes personal attributes such as being adaptable and possessing an inner strength that allows for positive adjustment to adverse circumstances (Bell, 2001). Positive psychologists have done much work on these attributes. For example, Kashdan and Rottenberg (2010) stress "psychological flexibility" in confronting situations of change. Also prized is "the ability to bounce back from negative emotional experiences" (Tugade, Fredrickson, \& Barrett, 2004: 1168). This school of thought argues that all young people have the potential to be resilient; it is a potential that can be both actualized and augmented (Waller, 2001).

Yet resilience is not only an attribute possessed by individuals; wider ecological systems and social systems can also be resilient (Brand \& Jax, 2007). Indeed, the social-ecological literature provides conceptual resources for finding more rules of thumb. The content of the social ecology concept of resilience is not dissimilar to the content of its psychological counterpart. Though the emphasis is on adapting to changing environmental conditions (cf. Pelling, 2011; Nelson, Adger, \& Brown, 2007), strong uncertainty features centrally in this field of enquiry (even if it is not explicitly named as such). The concept of social resilience can easily be transposed across to the basic question. Resilient socioeconomic arrangements provide material support to those in need, as wider processes of economic, political and social transformation occur apace. Robotization is a case in point. One proposal, for example, is to mitigate robotization-driven income inequality by increasing worker ownership of capital (Freeman, 2015).

What makes individual-level and social-level resilience a sensible enabling strategy for coping with the effects of robotization on future jobs? The answer 
lies in the concept of strong uncertainty itself. Strong uncertainty means that academics, policymakers, subject-matter experts of all stripes, and members of the general public to boot, simply do not know how widespread the job loss due to robotization is going to be. As a result, investing in measures to increase the broad preparedness of young people to face that future, and empowering them as citizens to shape that future, is just as rational, if not more so, than targeting the formation of specific job-focused skills - which may be outmoded before any such skills formation strategy comes to fruition.

The psychological literature is replete with proposals to boost resilience in the young (Masten \& O'Dougherty Wright, 2010). It would take us too far afield to comment on the many possible approaches, so we discuss just one: mindfulness training. This meditative training seeks to evoke, elicit, and extend the potential young people already possess for dealing with adversity. The vast literature on mindfulness training offers many perspectives that can be useful for dealing with the robotization challenge (e.g. Jacobs \& Blustein, 2008; Monshat et al., 2011). We will briefly comment only on a handful of recent contributions as an illustration of the fruitful insights than can be found in the literature in question.

Roeser (2014) provides a systematic review of the human developmental theses that underpin the targeting of a specific population group - young people - through a mindfulness approach within school settings. There are two points of interest closely related to our basic question. First, young people tend to be better absorbers of mindfulness training (Roeser, 2014: 384). Second, mindfulness is one of the "evolved, early-arising capacities of human beings" but it needs "cultural training and support to fully flower" (Roeser, 2014: 385). These points suggest that school-based mindfulness training - on which there are many studies attesting to its resilience-enhancing effects (for a review, see Meiklejohn et al., 2012) - can help young people to be resilient in the face of the challenge posed by robotization. A recent study attests to the complementarity between the inculcation of mindfulness and the creation and sustenance of a future-oriented "narrative of hope" (Moses and Chowdhury, 2016: 456).

Further, as suggested by political scientists and educationists (Mathiowetz, 2016; Comstock, 2015; Hyde \& LaPrad, 2015), mindfulness training is a forming ground of democratic citizens. If the cited authors are correct, this training can - through its effect on political engagement - build social resilience. This is important because increased social resilience does not just happen; in a liberal democratic environing context it requires a concerned, critically engaged citizenry prepared to push policymakers to respond to the robotization challenge. Whether this is through extending worker ownership (as per Freeman's suggestion mentioned above), creating a guaranteed basic income, or some other means is immaterial. Absent a citizenry actively 
engaged in politics, resilient social arrangements are unlikely to develop; they need a political spur.

\section{Summary and Concluding Remarks}

Due to the strong uncertainty provoked by the dizzying speed of invention in robotics and artificial intelligence, whether robotization will cause technological unemployment, and the extent of this unemployment, is a pressing question. As we have argued (2.3), the notion that technological unemployment is inevitable is, at minimum, plausible. This unquestionably raises the spectre of joblessness. To the extent that this has the potential to provoke despair in young people, the question of how to deal with the problem is pushed to the forefront of labour studies.

This paper's discussion of the phenomenon of technological unemployment and its corollary, strong uncertainty, is an important steppingstone to finding an answer. The existence of strong uncertainty in a fundamental way rules out any attempt at optimization. This uncertainty also rules out probabilistic reasoning and inductive argumentation along with it. How is it possible to be rational when thinking about future developments when inductive reasoning fails? In these circumstances, we believe, a rational response to the robotization challenge can be crafted using the notion of coping behaviour. Coping behaviour under conditions of strong uncertainty is based on two pillars: a narrative and a set of heuristics. A specific description of these two pillars leads to a coping strategy.

In broad terms, the coping strategy we have suggested can be easily summarized. The narrative consists of providing information to the populace about the pervasive diffusion of robotics and its potentially devastating economic consequences. This would avoid the tendency towards complacency and denial that happens whenever existential threats occur (Wittes \& Blum, 2015). The central focus of the narrative would emphasize that robotization is a challenge over which humanity can prevail, rather than a threat to which it will succumb. This would avoid a culture of defeatism and reinforce a positive, proactive frame of mind. Positive psychology is the narrative's legitimating scholarly prop. As to the set of heuristics, we proffer a triad of rules of thumb: investment in uniquely human social and emotional skills, resilience arrangements to allow positive adjustment, and a mindfulness approach to strengthen the power of resilience.

This topic cannot be dealt with exhaustively in a few pages. Still, it would not be difficult to amplify the foregoing argument or to find new avenues of research to design complementary answers to our paper's basic question. We hope to have carried the analysis far enough to provide a broad framework in which to discuss solutions to the social problems posed by the robot revolution. 


\section{NOTES}

1. Parenthetically, it is worthwhile mentioning that Keynes (1930: 325) goes on to say that "this is only a temporary phase of maladjustment," predicting a future of leisure and plenty one hundred years hence. This prophecy was reinforced by Schumpeter's 1942 encomium to "creative destruction" (Schumpeter, 2010).

2. Due to the concept's equivocal nature, the language of uncertainty can be confusing. The original dichotomy introduced by Knight (in a work first published in 1921) was risk/uncertainty, not weak uncertainty/strong uncertainty. For Knight, "risk" is "measurable uncertainty" and "true uncertainty" is "unmeasurable uncertainty" (Knight, 1965: 20). In another vein, strong uncertainty is tantamount to what environmental scholars, especially in the domain of climate change, refer to as "deep uncertainty" (Kasperson, 2008).

3. That such a public narrative is emergent is illustrated, for example, by the recent newspaper article by Avent (2016): "Robots will eventually do all our jobs, but we need to start planning to avert social collapse."

\section{REFERENCES}

Avent, R. (2016). "A World without Work Is Coming - It Could Be Utopia or It Could Be Hell," The Guardian, 19 September.

Barrat, J. (2013) Our Final Invention: Artificial Intelligence and the End of the Human Era. New York: St. Martin's Press.

Bell, C. C. (2001). "Cultivating Resiliency in Youth," Journal of Adolescent Health 29(5): 375-381.

Brand, F. S., \& Jax, K. (2007). "Focusing the Meaning(s) of Resilience: Resilience as a Descriptive Concept and a Boundary Object," Ecology and Society 12. Online publication. http://www.ecologyandsociety.org/vol12/iss1/art23/.

Brynjolfsson, E., \& McAfee, A. (2011). Race against the Machine: How the Digital Revolution Is Accelerating Innovation, Driving Productivity, and Irreversibly Transforming Employment and the Economy. Lexington, MA: Digital Frontier Press.

Comstock, P. W. (2015). "The Politics of Mindfulness," Democracy \& Education 23(2): 1-4.

Crisp, R., \& Powell, R. (2016). "Young People and UK Labour Market Policy: A Critique of 'Employability' as a Tool for Understanding Youth Unemployment," Urban Studies 54(8): 1784-1807.

Danaher, J. (2016). "Will Life Be Worth Living in a World without work? Technological Unemployment and the Meaning of Life," Science and Engineering Ethics 23(1): 41-64.

Earl, P. E., \& Littleboy, B. (2014). G.L.S. Shackle. Basingstoke: Palgrave Macmillan.

Feser, E. (2017). Five Proofs of the Existence of God. San Francisco, CA: Ignatius Press.

Ford, M. (2015). Rise of the Robots: Technology and the Threat of a Jobless Future.

New York: Basic Books. 
Freeman, R. B. (2015). "Who Owns the Robots Rules the World," IZA World of Labor 5: 1-10.

Frey, C. B., \& Osborne, M. A. (2013). "The Future of Employment: How Susceptible Are Jobs to Computerisation," Working Paper, Oxford Martin School. Retrieved 20 September, 2016 from http://www.oxfordmartin.ox.ac.uk/downloads/academic/future-of-employment.pdf

Hanson, R. (2016). The Age of EM: Work, Love, and Life when Robots Rule the Earth. Oxford: Oxford University Press.

Headrick, D. R. (2009). Technology: A World History. Oxford: Oxford University Press.

Hyde, A. M., \& LaPrad, J. G. (2015). "Mindfulness, Democracy, and Education," Democracy \& Education 23(2): 1-12.

Iniyatulla, S., Izgarjan, A., Kuusi, O., \& Minkkinen, M. (2016). "Metaphors in Futures Research," Futures 84: 109-114.

Jacobs, S. J., \& Blustein, D. L. (2008). "Mindfulness as a Coping Mechanism for Employment Uncertainty," The Career Development Quarterly 57(2): 174-80.

Kanter, R. M. (1995). "Careers and the Wealth of Nations: A Macro-perspective on the Structure and Implications of Career Forms," in M. B. Arthur, D. T. Hall, \& B. S. Lawrence (eds.), Handbook of Career Theory. Cambridge: Cambridge University Press, 506-521.

Kashdan, T. B., \& Rottenberg, J. (2010). "Psychological Flexibility as a Fundamental Aspect of Health," Clinical Psychology Review 30(7): 865-878.

Kasperson, R. E. (2008). "Coping with Deep Uncertainty: Challenges for Environmental Assessment and Decision-making," in G. Bammer \& M. Smithson (eds.), Uncertainty and Risk: Multidisciplinary Perspectives. London: Earthscan, 337348.

Keynes, J. M. (1930). "Economic Possibilities for Our Grandchildren," in The Collected Writings of John Maynard Keynes, Vol. IX, Essays in Persuasion. Cambridge: The Royal Economic Society, 321-332.

King, M. (2016). The End of Alchemy: Money, Banking, and the Future of the Global Economy. New York: W. W. Norton \& Company.

Knight, F. H. (1965). Risk, Uncertainty and Profit. New York: Harper \& Row Publishers.

Loi, M. (2015). "Technological Unemployment and Human Disenhancement," Ethics and Information Technology 17(3): 201-210.

Marchant, G. E., Stevens, Y. A., \& Hennessy, J. M. (2014). "Technology, Unemployment and Policy Options: Navigating the Transition to a Better World," Journal of Evolution \& Technology 24(1): 26-44.

Masten, A. S. (2014). Ordinary Magic: Resilience in Development. New York: The Guilford Press.

Masten, A. S., \& O'Dougherty Wright, M. (2010). "Resilience over the Lifespan: Developmental Perspectives on Resistance, Recovery, and Transformation," in J. W. Reich, A. Zautra, \& J. S. Hall (eds.), Handbook of Adult Resilience. New York: The Guilford Press, 213-237.

Mathiowetz, D. (2016). “'Meditation Is Good for Nothing:' Leisure as a Democratic Practice," New Political Science 38(2): 241-255. 
Meiklejohn, J., Phillips, C., Freedman, M. L., Griffin, M. L., Biegel, G.,, Roach, A., Frank, J., Burke, C., Pinger, L., Soloway, G., Isberg, R., Sibinga, E., Grossman, L., \& Saltzman, A. (2012). "Integrating Mindfulness Training into K-12 Education: Fostering the Resilience of Teachers and Students," Mindfulness 3(4): 291-307.

Milojevic, I., \& Iniyatulla, S. (2015). "Narrative Foresight," Futures 73: 151-162.

Monshat, K., Khong, B., Hassed, C., Vella-Brodrick, D., Norrish, J., Burns, J., \& Herrman, H. (2013). “'A Conscious Control over Life and My Emotions:' Mindfulness Practice and Healthy Young People. A Qualitative Study," Journal of Adolescent Health 52(5): 572-577.

Moses, J., \& Choudhury, S. (2016). “A 'Mechanism of Hope': Mindfulness, Education, and the Developing Brain," in R. E. Purser, D. Forbes, \& A. Burke (eds.), Handbook of Mindfulness: Culture, Context, and Social Engagement. Berlin: Springer, 447-458.

Nazareth, D. (2015). "Robotics and AI: Impacts Felt on Every Aspect of Our Future World," in B. Goertzel \& T. Goertzel (eds.), The End of the Beginning: Life, Society and Economy on the Brink of the Singularity. Los Angeles, CA: Humanity+ Press, 131-148.

Nelson, D. R., Adger, W. N., \& Brown, K. (2007). "Adaptation to Environmental Change: Contributions of a Resilience Framework," Annual Review of Environment and Resources 32: 395-419.

Pelling, M. (2011). Adaptation to Climate Change: From Resilience to Transformation. Abingdon: Routledge.

Peters, M. A. (2016). "Technological Unemployment: Educating for the Fourth Industrial Revolution," Educational Philosophy and Theory 49(1): 1-6.

Radinsky, W. (2015). "Robotics, AI, the Luddite Fallacy and the Future of the Job Market," in B. Goertzel \& T. Goertzel (eds.), The End of the Beginning: Life, Society and Economy on the Brink of the Singularity. Los Angeles, CA: Humanity+ Press, 159-185.

Roeser, R. W. (2014). "The Emergence of Mindfulness-based Interventions in Educational Settings," in Stuart A. Karabenick \& Timothy C. Urdan (eds.), Advances in Motivation and Achievement. Vol. 18, Bingley: Emerald, 379-419.

Ricardo, D. (1911). The Principles of Political Economy and Taxation. London: Everyman's Library.

Saner, M. \& Wallach, W. (2015). "Technological Unemployment, AI, and Workplace Standardization: The Convergence Argument," Journal of Evolution and Technology 25(1): 74-80.

Schumpeter, J. A. (2010). Capitalism, Socialism and Democracy. Abingdon: Routledge Classics.

Schwab, K. (2017). The Fourth Industrial Revolution. New York: Crown Business.

Sewell, W. H. (2005). Logics of History: Social Theory and Social Transformation. Chicago, IL: The University of Chicago Press.

Shackle, G. L. S. (1938). Expectations, Investment and Income. Oxford: Oxford University Press.

Shackle, G. L. S. (1955). Uncertainty in Economics and Other Reflections. Cambridge: Cambridge University Press. 
Spitzer, R. (2015). The Soul's Upward Yearning: Clues to Our Transcendent Nature from Experience and Reason. San Francisco, CA: Ignatius Press.

Standing, G. (2011). The Precariat: The New Dangerous Class. London: Bloomsbury Academic.

Staley, D. J. (2002). “A History of the Future,” History and Theory 41(4): 72-89.

Stiegler, B. (2015). "Automatic Society 1: The Future of Work - Introduction," La Deleuziana 1: 121-140.

Tugade, M. M., Fredrickson, B. L., \& Barrett, L. F. (2004). "Psychological Resilience and Positive Emotional Granularity: Examining the Benefits of Positive Emotions on Coping and Health," Journal of Personality 72(6): 1161-1190.

Waller, M. A. (2001). "Resilience in Ecosystemic Context: Evolution of the Concept," American Journal of Orthopsychiatry 71(3): 290-297.

Wilson, S., \& Ebert, N. (2013). "Precarious Work: Economic, Sociological and Political Perspectives," The Economic and Labour Relations Review 24(3): 263278.

Wittes, B., \& Blum, G. (2015). The Future of Violence: Robots and Germs, Hackers and Drones. New York: Basic Books.

Zappia, C. (2014). "Non-Bayesian Decision Theory ahead of Its Time: The Case of G. L. S. Shackle," Cambridge Journal of Economics 38(5): 1133-1154. 